\title{
Market segmentation variables as moderators in the prediction of business tourist retention
}

\author{
Magdalena Petronella Swart • Gerhard Roodt
}

Received: 4 December 2013/Accepted: 18 March 2014/Published online: 8 April 2014

(C) The Author(s) 2014. This article is published with open access at Springerlink.com

\begin{abstract}
This study explores whether five market segmentation variables moderate the relationship between the business tourist service quality scorecard (SQSC) and business tourist satisfaction (Satisfaction); or the relationship between the SQSC and business tourist retention (Retention). A cross-sectional field survey of South African business tourists yielded a sample of 498 respondents. Moderated multiple regression (MMR) analyses were used to investigate possible moderating effects. Findings suggest there are full moderation effects for gender in both the relationships between SQSC and Retention as well as Satisfaction and Retention. Partial moderation effects were evident for age and province. This study provides insights to enable business tourist managers to improve the service quality needs of each of the identified market segments, such as gender and age.
\end{abstract}

Keywords Market segmentation - Business tourist service quality scorecard - Business tourist satisfaction - Business tourist retention · Moderation

\section{Introduction}

South Africa is the premier business tourism destination in Africa and is amongst the top 15 long-haul business tourism destinations globally (Anon 2013). Service

\footnotetext{
M. P. Swart ( $\square)$

Department of Industrial Psychology and People Management, University of Johannesburg, Auckland Park, South Africa e-mail: mpswart@yahoo.com

G. Roodt

Faculty of Management, University of Johannesburg, PO Box 524, Auckland Park, Gauteng, South Africa

e-mail: groodt@uj.ac.za
} 
excellence is one of the key pillars in the National Tourism Sector Strategy (NTSS) in South Africa (NDT 2011). Therefore, Swart and Roodt (2008, 2009) proposed the development of SQSC in predicting Retention to address tourist satisfaction and the need to create service excellence (Alegre and Garau 2010) in South Africa. Consumer research indicates that service satisfaction mediates the relationship between service quality and customer retention (Dabholkar et al. 2000). This model proved to be a reliable and valid service quality measurement instrument for the business tourism industry (Swart and Roodt 2011a), while partial mediation through satisfaction is also evident (Chang and Polonsky 2012; Swart and Roodt 2011b). An investigation of market segmentation variables have become synonymous in tourism industry related research (Forgas-Coll et al. 2013; Kim et al. 2009a; Li et al. 2013; Rid et al. 2014). However, none of the identified studies indicated a moderating effect in the prediction of Retention through a SQSC. The objective of this paper is to investigate how the inclusion of market segmentation variables in linear relationships may influence the scores on the SQSC and Retention or Satisfaction and Retention. Furthermore, this paper proposes that the assessment of the different SQSC and Satisfaction levels in the prediction of Retention can be investigated in more detail. In this sense, understanding the differences amongst business tourists' profiles, such as the SQSC and its influence on satisfaction, between men and women, the different age groups, levels of education, different ethnic groups and the provinces visited, is fundamental to business tourism managers that aim to foment business tourist retention. This allows for South African business tourism managers to improve on their operational effectiveness and efficiency by addressing the service quality needs of each of the identified market segments. Multiple regression analyses allow for flexibility in the coding of the categorical variables for better differentiation in results of the market segments, which is of importance in this paper. This includes a literature review to support the research methods, results, discussion and conclusion.

\section{Theoretical orientation and literature review}

Against the background of Fishbein and Ajzen's (1975) Behavioural Intentions Model (Cognition $\rightarrow$ Affect $\rightarrow$ Intention $\rightarrow$ Behaviour), Swart and Roodt (2008, 2009) investigated how scores on a SQSC (cognition) are related to Retention (intention) scores, and how this relationship is meditated by Satisfaction (affect) scores and moderated by market segmentation variables. This resulted in a Business Tourist SQSC Prediction Model (Swart 2013). This paper aims to investigate the moderating relationship of the market segmentation variables between either the SQSC and Retention or Satisfaction and Retention.

According to research done by Ryan and Bonfield (1975), a market segmentation variable is an antecedent variable which has an influence on, but does not explain the relationships between independent (such as the SQSC) and dependent (such as Retention) variables. Furthermore, Chen et al. (2013) state service quality may influence the evaluation of service quality and satisfaction. It also clarifies the influences that precede these relationships. The weightings associated with the 
normative and attitudinal components of the model are different across the market segments and, therefore, it is expected that the market segmentation variables, as moderating variables, have an effect on the SQSC (independent variable) and Retention (dependent variable) (Baron and Kenny 1986; Frazier et al. 2004).

Targeting the right customers for a specific customer retention campaign is a high priority (Coussement and Van den Poel 2009). According to Seo et al. (2008), age and gender as market segmentation variables indirectly impact whether a customer will return to an organisation to experience the same product or service. However, they also indicate that more research is needed on other demographics such as education level, and area code (indicating the geographical area or province to which the business tourist travels) to better understand customer retention. Customers' age groups and levels of education contribute to the explanation of their tendency to return to an organisation (Cohen et al. 2007). Although it has been postulated that Satisfaction facilitates Retention at a destination, is it also important to identify which market segmentation variables will moderate the results of the SQSC. Identifying such variables will potentially contribute to a more favourable experience, leading to Retention. Thus for the purpose of this study, market segmentation variables are defined as the division of the business tourism market into smaller groups of delegates according to their gender, age, ethnic group, educational qualifications, province visited, and needs and characteristics when they are exposed to a business tourism product (as informed by George 2011; Moore et al. 2008).

Researchers have found that demographic variables (such as age and gender) play an important role in product adoption behaviours (Im et al. 2003) and in tourism (Han and Ryu 2006; Li et al. 2013). According to Hudson (1999), psychological forces do not operate in isolation. Mediating and moderating effects have been established in hospitality (Ro 2012), but not in a business tourism context before. Baron and Kenny (1986, p. 1181) are of the opinion that appropriate procedures need to be applied to make the most effective use of the moderator and mediator distinction (in the context of a 'wide range of phenomena', which can include attitude and personality traits) in a causal relationship. Moderators and mediators function on three levels, namely from a conceptual (explanations for differences in peoples' behaviour), strategic (moderators are introduced when there is an inconsistent relationship between the dependent and independents variables), and statistical (indicates the moderating effect of the dependant variable on the independent variable). Moderators may contain either manipulations or assessments, which can be either personal or situational variables. Thus, a moderator is defined as '... a qualitative (e.g. gender, ethnic group) or quantitative (e.g. level of reward) variable that affects the direction and/or strength of the relationship between an independent or predictor variable and a dependent or criterion variable' (Baron and Kenny 1986, p. 1174). Furthermore, multiple regression can be used to examine whether the effects of the predictor or moderator variables are continuous (e.g. as in the case of age) or categorical (e.g. as in the case of gender or ethnic group) (Frazier et al. 2004).

Service quality has a significant relationship with gender (Lee et al. 2011). However, age does not have a significant effect on the link between customer 
satisfaction and repeat visit intention (Han and Ryu 2006), while educational qualification has a significant relationship with customer satisfaction and perceived quality (Forgas-Coll et al. 2013; Severt et al. 2007). Aguinis (2004) further recommend the inclusion of gender and ethnicity as a best practice in the testing of moderation effects. Based on these findings, Chen et al. (2013) and Seo et al. (2008) recommend further research into the moderation effects of market segmentation variables. Supported by literature, specifically Seo et al. (2008), there is a need to further investigate these moderating relationships in the business tourism industry.

Gender, age, ethnic group, educational qualifications and province most frequently visited are identified as market segmentation variables in this study. Research on these variables is reported below.

\subsection{Gender}

Gender is one of the most popular segmentation strategies used to understand customers' attitudes, behaviours and choices (Crouch et al. 2009; Wakefield and Baker 1998) from a multi-channel context (Lin 2011). Gender is defined as the applicable characteristics, such as attitudes, behaviours, roles and values chosen by the male or female respondent (as informed by George (2011); Palan (2001)). Studies found that gender is a moderator in the relationship between quality and loyalty (Costa et al. 2001, Mittal and Kamakura 2001; Sanchez-Franco et al. 2009), but also between perceived quality and satisfaction (Forgas-Coll et al. 2013) in a service environment. Furthermore, a significant difference in the evaluation of service quality between male and female customers is observed, with female customers showing a tendency to rate service quality lower than males do (Lee et al. 2011; Snipes and Thomson 2006). From a tourism perspective, studies have been conducted on the influence of gender segmentation strategy (Lee et al. 2011); the effects of gender within a restaurant environment (Kim et al. 2009b) and the moderating effect of gender on airline website loyalty formation (Forgas-Coll et al. 2013). According to Kim et al. (2009b), gender is one of the most influential demographic variables associated with consumer purchase behaviour within a tourism-related environment. However, of all the identified studies, only the one conducted by Lee et al. (2011) support the moderating effect of gender and perceived service quality within a tourism environment, where a significant relationship is reported between men's perceptions of service quality and women's perceptions of service quality. All the other studies acknowledge the effect of gender, but only indicate the descriptive statistics. On the basis of the literature referenced it is clear that there is a literature gap regarding the moderating effect of gender in the prediction of tourist retention either via the SQSC or Satisfaction. Based on the above discussion, the following hypothesis is proposed:

$\mathbf{H}_{\mathbf{1 . 1}}$ Gender group moderates the relationship between SQSC and Retention.

$\mathbf{H}_{\mathbf{1 . 2}}$ Gender group moderates the relationship between Satisfaction and Retention. 


\subsection{Age}

Customers' age usually plays an important role in their choice to return to a specific service provider (Cohen et al. 2007; Crouch et al. 2009; Kim et al. 2009a). Age has been used as a market segmentation variable by 'Dividing a market into different age and lifecycle groups' (George 2011, p. 551). Therefore, age is defined as a generational market segment that represents a group of business tourists of a similar age who were born during the same time in history (as adapted from George 2011, p. 551; Wiersma 2009, p. 240). In a study on the tourism industry, Kim et al. (2009b) report that age is the most influential demographic variable associated with tourist purchase behaviour. It was further found that older tourists tend to show a higher repeat patronage than their younger counterparts (Kim et al. 2009b). Empirical evidence indicates that age is a moderator in the relationship between customer satisfaction and behavioural intention (Homburg and Giering 2001). Han and Ryu (2006) investigate the moderating effect of age in the relationship between tourist satisfaction and tourist repurchase intention, and have found that it is not significant. This finding should be further investigated in a business tourism context. No studies could be found on the moderating effect of age in the prediction of Retention. Based on the literature discussion, there is sufficient theoretical evidence to formulate the hypothesis:

\section{$\mathbf{H}_{2.1}$ Age groups moderate the relationship between SQSC and Retention. \\ $\mathbf{H}_{2.2}$ Age groups moderate the relationship between Satisfaction and Retention.}

\subsection{Ethnic group}

Many scholars have conducted research on ethnicity in tourism (Ishii 2012; Sabiote et al. 2013), but the moderating effect of ethnicity in the relationships between satisfaction, retention and service quality is limited. There is a close relationship between culture and ethnic group, since ethnic group represents the multiple traits of people of which culture can be one. Kong and Jogaratnam (2007, p. 278) state that 'Different cultures imply different mental programming that governs activities, motivations, and values'. In general nationality has been used to measure ethnicity in customer studies (Tsoukatos and Rand 2007), but only in descriptive statistics to characterise the population. From a tourism perspective, different studies (Hsieh and Tsai 2009; Liu and Jang 2009; Pizam 1999; Sabiote et al. 2013) have identified the influence of ethnicity on satisfaction and intention to return. Results from these studies demonstrated that local residents and tourism employees perceive tourists' behaviour to be affected by their national culture. More specifically the moderating effect of ethnicity on the relationship between satisfaction and perceived quality is significant (Hsieh and Tsai 2009; Sabiote et al. 2013). However, none of the consulted studies indicate the moderating effect of an ethnic group on the relationship between the SQSC and the prediction of Retention. Therefore, the hypothesis below will be tested:

$\mathbf{H}_{3.1}$ Ethnic groups moderate the relationship between SQSC and Retention.

$\mathbf{H}_{3.2}$ Ethnic groups moderate the relationship between Satisfaction and Retention. 


\subsection{Educational qualification}

The impact of education is one of the most influential demographic variables associated with consumer purchase behaviour within a tourism-related environment (Kim et al. 2009b). Thus, consumers with formal education are likely to be better educated as consumers, and also likely to engage in a detailed information search process before making a purchase decision (Crouch et al. 2009). In tourism research, Forgas-Coll et al. (2013) as well as Pakdil and Aydin (2007) indicate that tourists' education level tends to have a significant influence on their expectations of, and satisfaction with, an airline service. Hye-Rin et al. (2009) and Severt et al. (2007) are of the opinion that there is a significant relationship between educational activities, overall satisfaction, word-of-mouth (WOM) communication, and the intent to return to a specific conference. Therefore, Severt et al. (2007) support the moderating effect of education on satisfaction amongst convention attendees. In the airline industry the moderating effect of education in the relationship between perceived quality and satisfaction is supported (Forgas-Coll et al. 2013). However, none of these studies investigate the moderating effect of educational qualification in predicting Retention through the SQSC. This study also aims to address the suggestion made by Seo et al. (2008) to test education as a moderating variable in order to create a better understanding of customer retention, especially in a business tourism context. There is thus sufficient theoretical evidence to formulate the hypothesis below:

$\mathbf{H}_{4.1}$ Educational qualification categories moderate the relationship between SQSC and Retention.

$\mathbf{H}_{\text {4.2 }}$ Educational qualification categories moderate the relationship between Satisfaction and Retention.

\subsection{Province (geographical region) visited}

Studies related to a government's geographical area have been done (Ishikawa and Fukushige 2007). Results from the identified studies focus only on local governments and municipalities and not on provinces per se. Furthermore, only the descriptive results and weights allocated in the balanced scorecard (BSC) survey were considered by Chan (2004), while Sullivan and Estes (2007) recommend the modification of the SERVQUAL model, and warn that private-sector models are not designed for public decision-making. It is evident from these studies that information on the application of the BSC, service quality dimensions, customer satisfaction and customer retention is limited within a business tourism context. However, due to the high ranking of some of South Africa's business tourist destinations, such as Gauteng and KwaZulu Natal, it is important to investigate whether a specific province's SQSC has an influence on the prediction of Retention. Hence, to create a better understanding of customer retention, Seo et al. (2008) suggest the investigation of a destination's geographical location as a dimension. Therefore, this study aims to investigate whether province most frequently visited (hereafter mostly referred to a province) moderates the relationship between the 


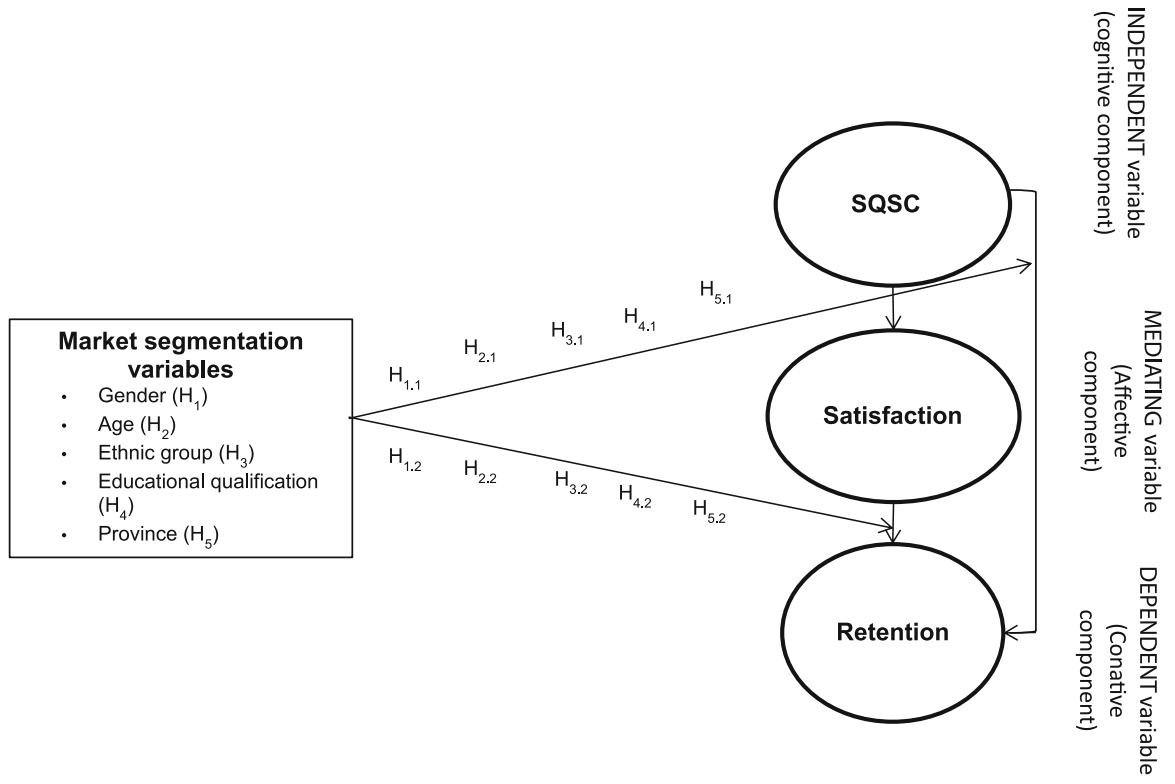

Fig. 1 Theoretical model

SQSC and Satisfaction, as well as between SQSC and Retention in a business tourism context. Thus, the following hypothesis is formulated:

$\mathbf{H}_{5.1}$ Provinces visited moderate the relationship between SQSC and Retention.

H5.2 $_{5}$ Provinces visited moderate the relationship between Satisfaction and Retention.

Figure 1 is proposed as theoretical model for this study. This model is based on the review of the literature and the relationships between the constructs in the hypotheses with the moderating effects of gender $\left(\mathrm{H}_{1}\right)$, age $\left(\mathrm{H}_{2}\right)$, ethnic group $\left(\mathrm{H}_{3}\right)$, educational qualification $\left(\mathrm{H}_{4}\right)$ and province $\left(\mathrm{H}_{5}\right)$, as shown below.

\section{Method}

\subsection{Research design}

The research design followed in this study will be briefly presented under the next two headings.

\subsubsection{Research approach}

A quantitative research approach was followed, while primary data was generated through a non-probability, cross-sectional survey on the business tourist population in South Africa. General linear modelling (GLM) techniques were applied in 
conducting the data analysis. The relationship between either the SQSC or Retention (first sub-hypothesis) or Satisfaction and Retention (second sub-hypothesis) were investigated to test the moderating effect of the identified market segmentation variables.

\subsubsection{Research method}

The research method is described under the following four headings:

\subsubsection{Sampling and participants A purposive, convenience sample of 498} respondents (business tourists) was sampled who were exposed to business tourism products/destinations, such as: game lodges, guest houses, three, four and five star hotels, conference centres as well as airlines. Respondents were represented from different tertiary academic institutions, associations, government and corporate industries. Data was collected between October 2009 and March 2010 in the South African business tourism industry.

3.1.2.2 Measuring instruments Swart and Roodt (2008, 2009) proposed three measurement instruments namely the SQSC, Satisfaction and Retention. The SQSC was compiled by superimposing the SERVQUAL model (Briggs et al. 2007; Burnkrant et al. 1982; Parasuraman et al. 1988) on the BSC (Kaplan and Norton 1992). Measures were taken to ensure that the items were evaluating cognitive aspects of the service quality experience (in terms of the Fishbein and Ajzen (1975) model). Four perspectives were obtained, namely Financial, Customer Value, Internal Business and Innovation and Learning, and were included in the final SQSC, which consisted of 46 items with an overall Cronbach reliability of .88. A seven-point intensity scale, anchored at extreme ends, was used to measure responses on each item for all three scales.

The Tourist Satisfaction scale consisted of 18 items and captures the affective component of the Fishbein and Ajzen (1975) model. These items were represented by five dimensions based on the following theoretical contributions, namely service satisfaction (Hutchinson et al. 2009; Pyon et al. 2009), experience (Brunner-Sperdin et al. 2012; Kaplan and Norton 2008; Pyon et al. 2009), WOM communication (George 2011; Hutchinson et al. 2009; Kaplan and Norton 2001; Kim et al. 2009a, b), accessibility (Chi and Qu 2008; Ekiz et al. 2009) and feelings (Hosany and Witham 2010; Taplin 2012). This scale yielded a Cronbach Alpha of .94.

For the measurement of Tourist Retention (the behavioural intentions in terms of the Fishbein and Ajzen model), four dimensions, namely repurchase intention (Dabholkar et al. 2000; Hutchinson et al. 2009; Udo et al. 2010), loyalty programme (Ha and Jang 2010; Loureiro and Kastenholz 2010), intensification (De Rojas and Camarero 2008) as well as excitement (Hosany and Witham 2010; Kim et al. 2010) were used. This construct consisted out of 10 items with a Cronbach reliability of .87 .

3.1.2.3 Research procedure Members of the business tourist population who met the sampling criteria were invited to participate in the e-survey received via a link to 
an e-invitation letter. Questionnaires were only available in English and also distributed through trained fieldworkers in a field setting.

3.1.2.4 Statistical analysis GLM techniques were applied to analyse the data, after which a Soper interaction was conducted. Multiple regression analyses for categorical moderators are used to investigate a moderating effect (Baron and Kenny 1986; Chou and Yeh 2013; Frazier et al. 2004; Ro 2012). The choice of a moderator as well as the hypothesis of the various interactions is based on the discussed theory. It is known that a moderator explains under what conditions or when $X$ (i.e. the SQSC) causes $Y$ (i.e. Retention) (Aguinis 2004; Ro 2012). Moderators were investigated in an attempt to improve the overall model fit, as the main effects alone may not offer sufficient precision in prediction (Aguinis 2004; Ro 2012). A MMR procedure was conducted, as this inferential procedure compares two different least-square regression equations. This procedure permits the researcher to make extrapolations of whether a moderating effect exists in the population, based on the sample data. A new variable is created when the product between the predictors are included as a third term in the regression (Aguinis 2004; Ro 2012). Calculations were generated by means of International Business Machines Corporation (IBM) Statistical Package for the Social Sciences (SPSS) programme Version 20.0.

\section{Results}

Ten general hypotheses $\left(\mathrm{H}_{1.1}-\mathrm{H}_{5.2}\right)$ were proposed in the literature discussion, to summarise the different relationships in the predictive model (Fig. 1). Two tables, namely the model analysis and model coefficients, are used to explain the results related to each sub-hypothesis. Whether a contribution has been made to the current body of knowledge and whether the research objectives have been achieved will be discussed in a summary. This format will be followed for all the discussions related to this paper.

\subsection{Market segmentation variable results related to the first sub-hypothesis}

The first sub-hypothesis tests if the market segmentation variables, namely gender, age, ethnic group, education or province, have a moderating effect on the relationship between the SQSC and Retention. Table 1 indicates the variance analyses for all five market segmentation variables.

It is evident from Table 1 that the $p$ value was significant for all five market segmentation variables, which allowed for a continuation of the analysis. Table 2 indicates the model coefficients for all five interaction analyses.

The results in Table 2 supported the presence of a moderating effect for gender as the $R^{2}$ contribution of SQSC $\times$ gender interaction explained a $1 \%$ variance in the model. The $R^{2}$ contribution of SQSC $\times$ age 1 explained a $1 \%$ variance in the model. Therefore, the data partially supported $\mathrm{H}_{\mathrm{A}}$, which implies that the 
Table 1 Model analysis of variance of market segmentation variables for SQSC in relation to retention

\begin{tabular}{|c|c|c|c|c|c|}
\hline Variable & Sum of squares & $d f$ & $M^{2}$ & $F$ & $\rho$ \\
\hline \multicolumn{6}{|l|}{ Gender } \\
\hline Regression & 264.84 & 3 & 88.28 & 149.37 & $\leq .001$ \\
\hline Residual & 288.43 & 488 & .60 & & \\
\hline Total & 553.27 & 491 & & & \\
\hline \multicolumn{6}{|l|}{ Age } \\
\hline Regression & 257.26 & 5 & 51.45 & 86.24 & $\leq .001$ \\
\hline Residual & 283.94 & 476 & .60 & & \\
\hline Total & 541.20 & 481 & & & \\
\hline \multicolumn{6}{|l|}{ Ethnic } \\
\hline Regression & 257.19 & 3 & 85.73 & 143.10 & $\leq .001$ \\
\hline Residual & 289.36 & 483 & .60 & & \\
\hline Total & 546.54 & 486 & & & \\
\hline \multicolumn{6}{|l|}{ Education } \\
\hline Regression & 263.88 & 5 & 52.78 & 88.85 & $\leq .001$ \\
\hline Residual & 286.31 & 482 & .60 & & \\
\hline Total & 550.20 & 487 & & & \\
\hline \multicolumn{6}{|l|}{ Province } \\
\hline Regression & 264.86 & 7 & 37.84 & 65.40 & $\leq .001$ \\
\hline Residual & 278.26 & 481 & .58 & & \\
\hline Total & 543.12 & 488 & & & \\
\hline
\end{tabular}

Dependent variable: Retention

$d f$ degrees of freedom, $M^{2}$ mean square, $F F$ ratio indicates the most variability between groups, $\rho$ probability value, Ethnic ethnic group, Education the Level of Education

moderating effect of age $1(Z)$ caused a change in the slope of the regression of Retention $(Y)$ on SQSC $(X)$, while the additional product term $(X \times Y)$ improved the fit of the model on the prediction of Retention $(Y)$.

The equation for gender and age were as follows:

$$
\begin{array}{r}
\text { Retention }=5.16+.94 \mathrm{SQSC}+.02 \text { gender }-.22(\mathrm{SQSC} \times \text { gender }) \\
\quad \text { Retention }=5.23+.78 \mathrm{SQSC}-.14 \text { age } 1+.22(\mathrm{SQSC} \times \text { age } 1)
\end{array}
$$

Another criterion across the moderator-based sub-groups was that the slopes had to differ across the different groups, for example the gender groups. Thus, the larger the difference in the slopes, the stronger the moderation. Table 3 gives the different slope values of the male and female groups as well as for the different age groups.

The results depicted in Table 3, indicate that the intercepts of the male (5.16) and female (5.18) groups were relatively close to one another. Furthermore, the simple slope of the male group (.94) was different to that of the female group (.07), while the difference in the slope of the male group (18.14) was larger than that of the female group (10.88). These results further support the strong moderation effect of gender in the relationship between the SQSC and Retention $\left(\mathrm{H}_{1.1}\right)$. Furthermore, the 


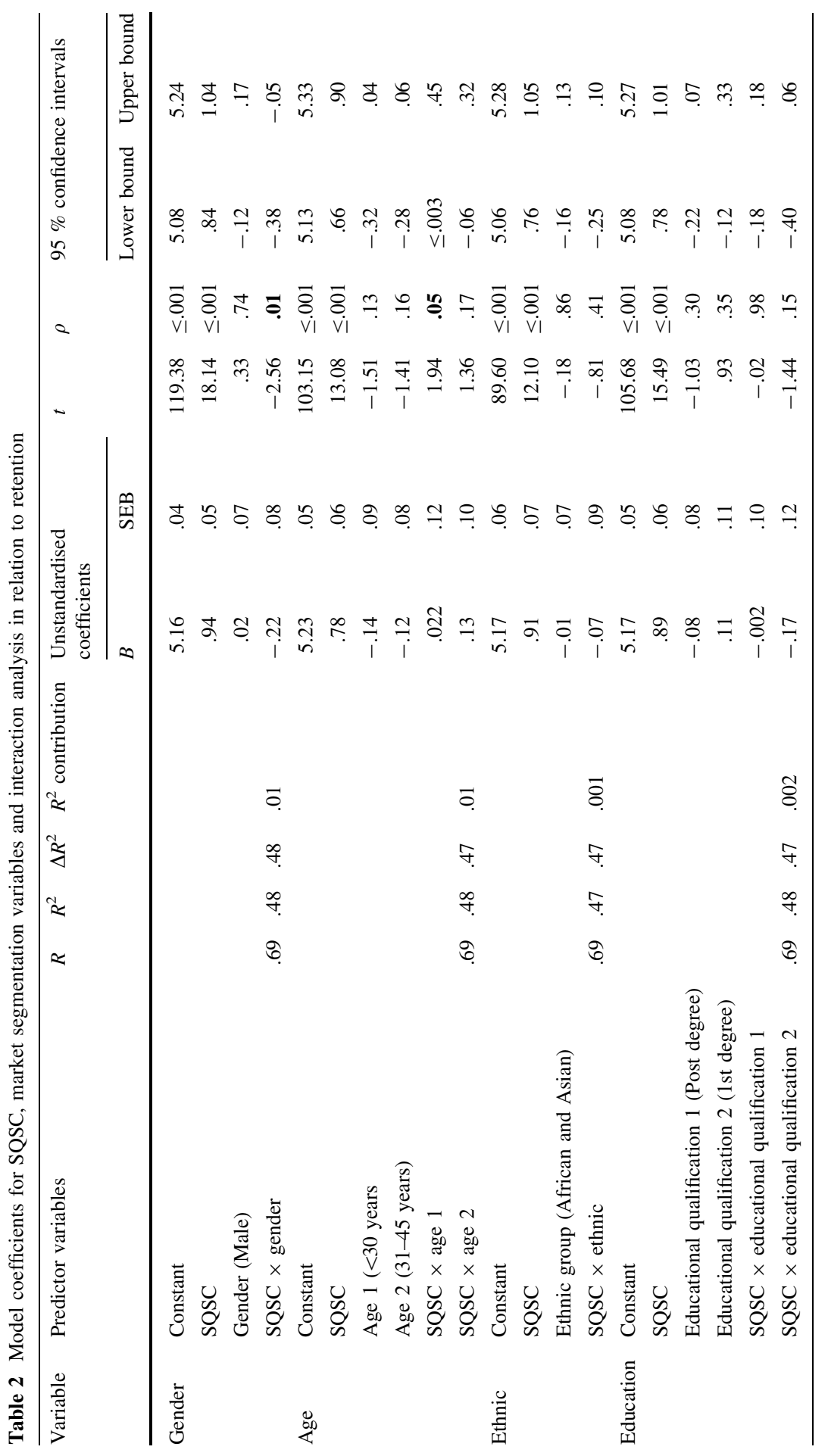




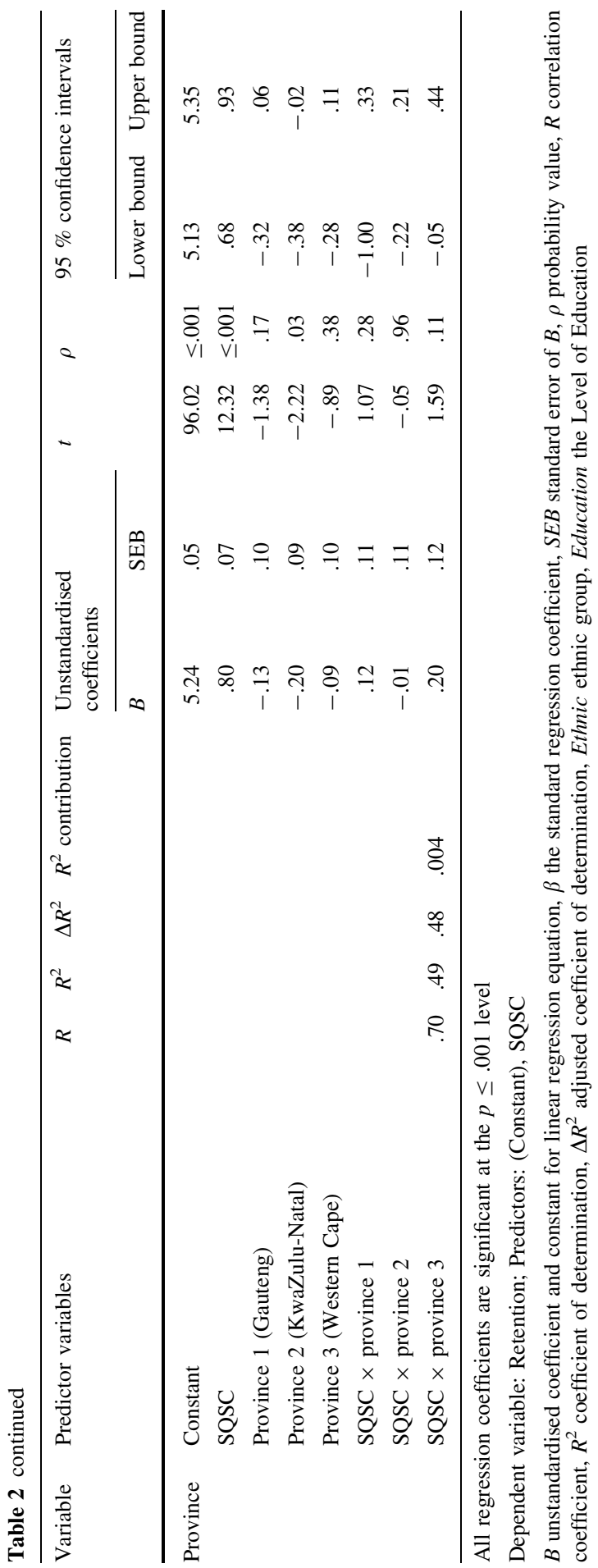


Table 3 Interaction of the SQSC with the male and female groups as well as for the different age groups in relation to Retention

\begin{tabular}{|c|c|c|c|c|c|c|c|c|c|}
\hline \multirow[t]{2}{*}{$\begin{array}{l}\text { Moderator } \\
\text { category } \\
\text { code }\end{array}$} & \multirow[t]{2}{*}{$\begin{array}{l}\text { Simple } \\
\text { slope }\end{array}$} & \multirow[t]{2}{*}{ Intercept } & \multirow[t]{2}{*}{$\begin{array}{l}S E B \text { of } \\
\text { simple } \\
\text { slope }\end{array}$} & \multirow[t]{2}{*}{$d f$} & \multirow[t]{2}{*}{$t$} & \multirow[t]{2}{*}{$\begin{array}{l}\rho \text { of } \\
\text { simple } \\
\text { slope } \\
\text { (2-tailed) }\end{array}$} & \multirow[t]{2}{*}{$\begin{array}{l}\rho \text { of } \\
\text { simple } \\
\text { slope } \\
\text { (1-tailed) }\end{array}$} & \multicolumn{2}{|c|}{$\begin{array}{l}95 \% \mathrm{CI} \\
\text { around } \\
\text { the simple } \\
\text { slope }\end{array}$} \\
\hline & & & & & & & & $\begin{array}{l}\text { Lower } \\
\text { bound }\end{array}$ & $\begin{array}{l}\text { Upper } \\
\text { bound }\end{array}$ \\
\hline \multicolumn{10}{|l|}{ Gender } \\
\hline Male & .94 & 5.16 & .05 & 488 & 18.14 & $\leq .01$ & $\leq .01$ & .84 & 1.04 \\
\hline Female & .07 & 5.18 & .07 & 488 & 10.88 & $\leq .01$ & $\leq .01$ & .59 & .86 \\
\hline \multicolumn{10}{|l|}{ Age } \\
\hline $31-45$ years & .78 & 5.23 & .06 & 476 & 13.08 & $\leq .01$ & $\leq .01$ & .66 & .90 \\
\hline $\begin{array}{l}30 \text { years and } \\
\text { younger }\end{array}$ & 1.00 & 5.09 & .10 & 476 & 10.18 & $\leq .01$ & $\leq .01$ & .81 & 1.20 \\
\hline
\end{tabular}

$S E B$ standard error of $B, d f$ degrees of freedom, $t$ coefficient of the slope, $\rho$ probability value

simple slope of the 30 years and younger group (1.00) was slightly stronger than that of the 31-45 years group (.78). The intercept of the 30 years and younger group (5.09) was slightly weaker than that of the 31-45 years group (5.23), which supported the partial moderating effect of age on the relationship between the SQSC and Retention $\left(\mathrm{H}_{2.1}\right)$. Model coefficients for SQSC, ethnic group $\left(\mathrm{H}_{3.1}\right)$, educational qualification $\left(\mathrm{H}_{4.1}\right)$ or province $\left(\mathrm{H}_{5.1}\right)$, and interaction analysis in relation to Retention did not support the presence of a moderating effect.

\subsection{Market segmentation variable results related to the second sub-hypothesis}

The second sub-hypothesis tests if the five market segmentation variables have a moderating effect on the relationship between the Satisfaction and Retention. Table 4 indicates the variance analyses for all five market segmentation variables.

It is evident from Table 4 that the $p$ value was significant for all five market segmentation variables, which allowed for a continuation of the analysis. Table 5 indicates the model coefficients for all five interaction analyses.

Results depicted in Table 5 indicate the model coefficients for Satisfaction, gender, Satisfaction $\times$ gender, age, Satisfaction $\times$ age 1 , Satisfaction $\times$ age 2, province and Satisfaction $\times$ province 3 in relation to Retention indicated the presence of a moderating effect. The $R^{2}$ contribution of Satisfaction $\times$ gender and Satisfaction $\times$ province 3 interactions explained $1 \%$ variance in the model, while the $R^{2}$ contribution of Satisfaction $\times$ age explained $2 \%$ variance in the model. Satisfaction $\times$ gender, Satisfaction $\times$ age 1 , Satisfaction $\times$ age 2 and Satisfaction $\times$ province 3 (interaction terms) had a $\rho$ value of less than .05 , indicating a statistically significant interaction. The data therefore supported $\mathrm{H}_{\mathrm{A}}$, which implies that the moderating effect of the market segmentation variables (gender, age or province) $(Z)$ cause a change in the slope of the regression of Retention $(Y)$ on Satisfaction $(X)$, while the additional product term $(X \times Y)$ improves the fit of the model on the prediction of Retention $(Y)$. 
Table 4 Model analysis of variance of market segmentation variables for satisfaction in relation to retention

\begin{tabular}{|c|c|c|c|c|c|}
\hline Variables & Sum of squares & $d f$ & $M^{2}$ & $F$ & $\rho$ \\
\hline \multicolumn{6}{|l|}{ Gender } \\
\hline Regression & 251.27 & 3 & 83.76 & 135.35 & $\leq .001$ \\
\hline Residual & 302.00 & 488 & .62 & & \\
\hline Total & 553.27 & 491 & & & \\
\hline \multicolumn{6}{|l|}{ Age } \\
\hline Regression & 256.09 & 5 & 51.21 & 85.51 & $\leq .001$ \\
\hline Residual & 285.11 & 476 & .60 & & \\
\hline Total & 541.20 & 481 & & & \\
\hline \multicolumn{6}{|l|}{ Ethnic } \\
\hline Regression & 245.98 & 3 & 81.99 & 131.76 & $\leq .001$ \\
\hline Residual & 300.57 & 483 & .62 & & \\
\hline Total & 546.54 & 486 & & & \\
\hline \multicolumn{6}{|l|}{ Education } \\
\hline Regression & 250.72 & 5 & 50.14 & 80.71 & $\leq .001$ \\
\hline Residual & 299.48 & 482 & .62 & & \\
\hline Total & 550.20 & 487 & & & \\
\hline \multicolumn{6}{|l|}{ Province } \\
\hline Regression & 265.11 & 7 & 37.87 & 65.53 & $\leq .001$ \\
\hline Residual & 278.01 & 481 & .58 & & \\
\hline Total & 543.12 & 488 & & & \\
\hline
\end{tabular}

Dependent variable: Retention

$d f$ degrees of freedom, $M^{2}$ mean square, $F F$ ratio indicates the most variability between groups, $\rho$ probability value, Ethnic ethnic group, Education the Level of Education

The equations were as follows:

$$
\begin{aligned}
\text { Retention }= & 5.18+.82 \text { Satisfaction }-.03 \text { gender }-.19(\text { Satisfaction } \times \text { gender }) \\
\text { Retention }= & 5.25+.62 \text { Satisfaction }-.07 \text { age } 1+.29(\text { Satisfaction } \times \text { age } 1) \\
\text { Retention }= & 5.25+.62 \text { Satisfaction }-.24 \text { age } 2+.27(\text { Satisfaction } \times \text { age } 2) \\
\text { Retention }= & 5.27+.68 \text { Satisfaction }-.07 \text { province } 3 \\
& +.22(\text { Satisfaction } \times \text { province } 3)
\end{aligned}
$$

Across the moderator-based sub-groups the slopes had to differ across the different groups, for example the gender groups. Thus, the larger the difference in the slopes, the stronger the moderation as mentioned before. Table 6 gives the different slope values of the gender, age and province groups.

From Table 6, it is evident that the intercepts of the male (5.18) and female (5.15) groups were relatively close to one another. Furthermore, the simple slope for the male group (.82) was different to that of the female group (.63), while the difference in the slope for the male group (17.62) was larger than that of the female group (9.70). These results further supported the strong moderation effect of gender 


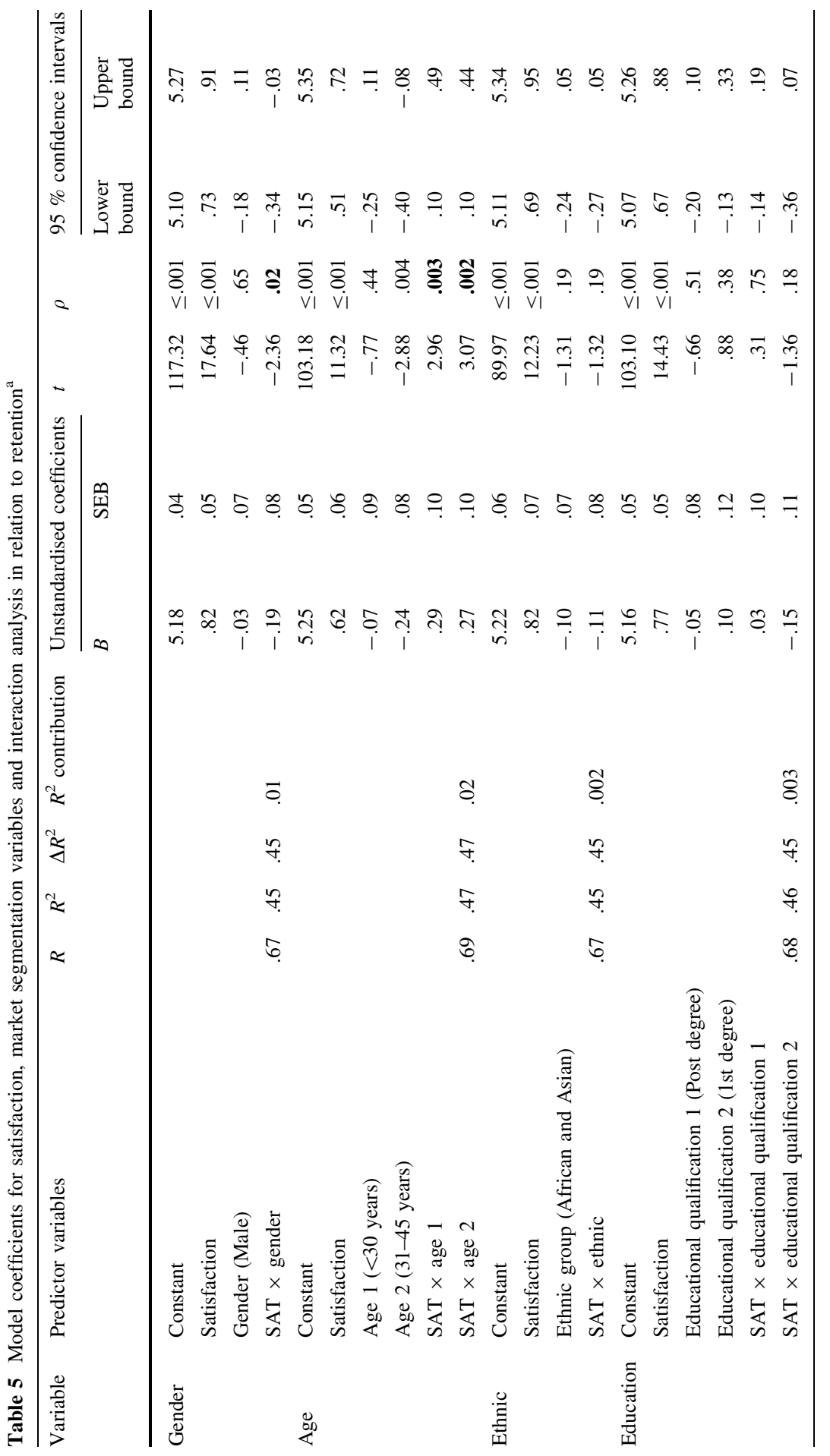




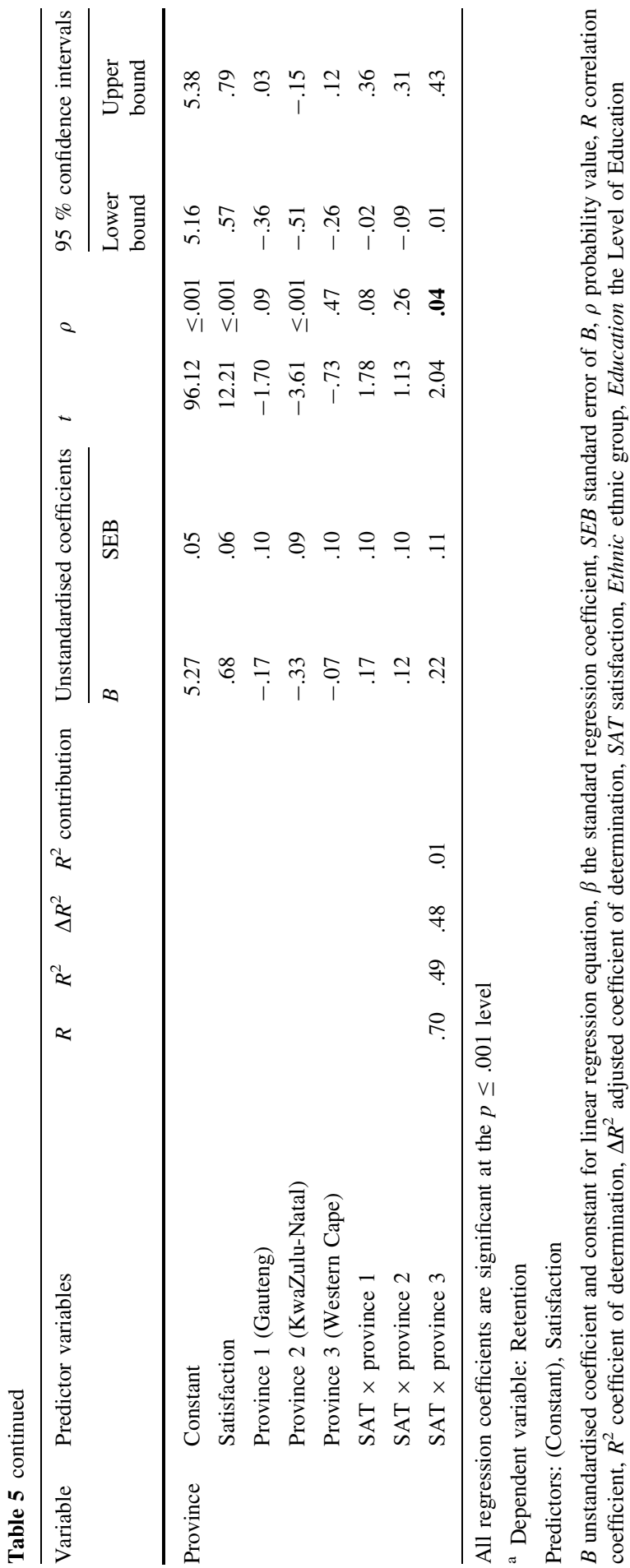

\section{(6) Springer}


Table 6 Interaction of Satisfaction with the male and female groups as well as for the different age groups in relation to Retention

\begin{tabular}{|c|c|c|c|c|c|c|c|c|c|}
\hline \multirow[t]{2}{*}{$\begin{array}{l}\text { Moderator } \\
\text { category code }\end{array}$} & \multirow[t]{2}{*}{$\begin{array}{l}\text { Simple } \\
\text { slope }\end{array}$} & \multirow[t]{2}{*}{ Intercept } & \multirow[t]{2}{*}{$\begin{array}{l}\text { SEB of } \\
\text { simple } \\
\text { slope }\end{array}$} & \multirow[t]{2}{*}{$d f$} & \multirow[t]{2}{*}{$t$} & \multirow{2}{*}{$\begin{array}{l}\rho \text { of } \\
\text { simple } \\
\text { slope } \\
\text { (2-tailed) }\end{array}$} & \multirow{2}{*}{$\begin{array}{l}\rho \text { of } \\
\text { simple } \\
\text { slope } \\
\text { (1-tailed) }\end{array}$} & \multicolumn{2}{|c|}{$\begin{array}{l}95 \% \text { CI } \\
\text { around the } \\
\text { simple slope }\end{array}$} \\
\hline & & & & & & & & $\begin{array}{l}\text { Lower } \\
\text { bound }\end{array}$ & $\begin{array}{l}\text { Upper } \\
\text { bound }\end{array}$ \\
\hline \multicolumn{10}{|l|}{ Gender } \\
\hline Male & .82 & 5.18 & .05 & 488 & 17.62 & $\leq .01$ & $\leq .01$ & .73 & .91 \\
\hline Female & .63 & 5.15 & .06 & 488 & 9.70 & $\leq .01$ & $\leq .01$ & .50 & .76 \\
\hline \multicolumn{10}{|l|}{ Age } \\
\hline $31-45$ years & .62 & 5.25 & .05 & 476 & 11.32 & $\leq .01$ & $\leq .01$ & .51 & .72 \\
\hline $\begin{array}{l}30 \text { years } \\
\text { and } \\
\text { younger }\end{array}$ & .91 & 5.18 & .08 & 476 & 10.96 & $\leq .01$ & $\leq .01$ & .75 & 1.07 \\
\hline \multicolumn{10}{|l|}{ Province } \\
\hline Gauteng & .68 & 5.27 & .06 & 481 & 12.21 & $\leq .01$ & $\leq .01$ & .57 & .79 \\
\hline $\begin{array}{l}\text { KwaZulu } \\
\text { Natal }\end{array}$ & .85 & 5.10 & .08 & 481 & 10.72 & $\leq .01$ & $\leq .01$ & .69 & 1.01 \\
\hline $\begin{array}{l}\text { Western } \\
\text { Cape }\end{array}$ & .79 & 4.94 & .09 & 481 & 9.29 & $\leq .01$ & $\leq .01$ & .62 & .96 \\
\hline
\end{tabular}

$S E B$ standard error of $B, d f$ degrees of freedom, $t$ coefficient of the slope, $\rho$ probability value

in the relationship between Satisfaction and Retention $\left(\mathrm{H}_{1.2}\right)$. The simple slope of the 30 years and younger group (.91) was different to that of the 31-45 years group (.62). The intercept of the 30 years and younger group (5.18) was slightly weaker than that of the 31-45 year group (5.25). These results partially supported the moderation effect of age in the relationship between Satisfaction and Retention $\left(\mathrm{H}_{2.2}\right)$. The simple slopes were different for Gauteng (.68), Western Cape (.79), and KwaZulu-Natal (.85). The intercept was the weakest for the Western Cape at 4.94, followed by KwaZulu-Natal (5.10), while the strongest was for Gauteng (5.27). These results support the moderation effect of province in the relationship between Satisfaction and Retention $\left(\mathrm{H}_{5.2}\right)$. Model coefficients for Satisfaction, ethnic group $\left(\mathrm{H}_{3.2}\right)$, educational qualification $\left(\mathrm{H}_{4.2}\right)$, and interaction analyses in relation to Retention did not support the moderating effect.

\section{Discussion}

The objective of the study was to explore whether the relationship between two quantitative variables, i.e. SQSC and Retention, changes based on the value of a discrete grouping variable, such as the market segmentation variables, to improve the overall model fit. Model analyses of variance of all five market segmentation variables for the SQSC in relation to Retention (Table 1) as well as for Satisfaction in relation to Retention (Table 2) had significant values. The model was tested to verify the hypotheses relating to identified variables (Tables 2,5 ). The results aim to 
advise business tourist managers on whether market segmentation variables can assist in the identification of the specific retention needs of business tourists.

Empirical verification of $\mathrm{H}_{1}$ reveals that the effect of gender on the relationship between the SQSC and Satisfaction as well as between Satisfaction and Retention is significant (Tables 2, 5). Thus, gender is a moderator in determining a business tourist's post-purchase behaviour, as was evident in a general consumer behaviour study by Wakefield and Baker (1998). The findings are in line with previous studies done in the tourism industry, where Lee et al. (2011) indicated the moderating effect of gender on service quality (now the SQSC) within a tourism environment. Furthermore, the moderating effect of gender in the relationship between perceived quality (now SQSC) and satisfaction (Forgas-Coll et al. 2013) is also supported. Therefore, this study makes a unique contribution by proposing that a gender effect is now also evident amongst business tourists. The interaction of the SQSC with the different gender groups in relation to Retention indicated that the female group's SQSC was lower than that of the male group, which supports the findings of Lee et al. (2011) as well as Snipes and Thomson (2006) (Table 3). Men tend to be selective in the way they process information and are less concerned with detail, while females are most likely to be more expressive and intuitive, focus on relationships and are sensitive towards their feelings for others. If any of these psychological aspects are jeopardised, the relationship between the SQSC and Retention becomes lower. The same results were evident in the relationship between Satisfaction and Retention, where the female group's Satisfaction was lower that than of the male group (Lee et al. 2011; Snipes and Thomson 2006) (Table 6). Women are probably more skilful in sending non-verbal messages and if they are dissatisfied with the service delivery in a business tourism environment they will hardly return to have the same experience. Possible reasons for these results are that women have higher service quality and satisfaction requirements before they will return to a specific business tourist destination, than men are, particularly in a context like that of South Africa, where the study was undertaken. This contribution offers new results to the literature on gender as a moderator of the SQSC Prediction Model. These results imply that the relationship between the SQSC and Retention is not only important in the measurement of service quality (through the SQSC), but also that it is critical to accommodate the different genders in this assessment.

Empirical verification of $\mathrm{H}_{2}$ shows that that age partially moderator in the relationship between Satisfaction and Retention (Table 5), which is in line with the research done by Homburg and Giering (2001). Consequently, and contrary to the research done by Han and Ryu (2006), this study does not support their findings which indicate an insignificant moderating effect of age in the relationship between tourist satisfaction and tourist repurchase intention. The partial moderating effect of age was also confirmed for the relationship between the SQSC and Retention (Table 5). The interaction of the SQSC with the different age groups in relation to Retention indicated that the group of 30 years and younger has a higher Retention score than the 31-45 years group (Table 6). Furthermore the interaction of Satisfaction with the different age groups in Retention indicated that the 30 years and younger group has a higher Retention score than the 31-45 years group (Table 6). A possible reason for these results is that the 30 years and younger group 
have not had as much exposure to business travel as the 31-45 years group and therefore have a limited frame of reference in the assessment of service quality and satisfaction needs in their decision to return to a destination. Another reason is that the group of 30 years are less sceptical and independent than the 31-45 years group. These results further imply that the younger group has a higher Retention score than the older group, which does not support the finding by Kim et al. (2009b). A unique contribution is made by confirming the partial moderating effect of age in the relationship with Satisfaction and Retention.

Empirical verification of $\mathrm{H}_{3}$ reveals that different ethnic groups do not moderate the relationship between the SQSC and Retention (Table 2), or the relationship between Satisfaction and Retention (Table 5). There is thus no empirical support for the proposed moderating effect. These results are in contrast with finding by Hsieh and Tsai (2009) as well as Sabiote et al. (2013), where the moderating effect of ethnicity on the relationship between satisfaction and perceived quality is supported. This might be the reason why literature mostly reported the on the descriptive statistics related to ethnic groups. It can be argued that most ethnic groups have the same service quality expectations with regards to business tourism and therefore have the same behaviour. These results provide evidence that ethnic group is not a moderator of the Business Tourist SQSC Prediction Model and make a contribution to the literature on ethnic groups.

Empirical verification of $\mathrm{H}_{4}$ shows that results from this study are not in line with previous tourism research which found that a tourist's education level tends to have a significant influence on that customer's expectations and satisfaction (Forgas-Coll et al. 2013; Pakdil and Aydin 2007) (Table 5). No empirical support for the moderating effect for the relationship between the SQSC and Retention is evident (Table 2). It is also not possible to confirm the results from Severt et al. (2007) on the moderating effect of education on satisfaction amongst convention attendees. This may be because business tourists have the same service quality and satisfaction behaviour to justify the return to a business tourist destination. Evidence is provided that educational qualification does not moderate the relationship between the SQSC and Retention, or the relationship between Satisfaction and Retention, which make a contribution the body of knowledge.

Turing to the final market segmentation variable, namely province, the findings address the suggestion by Seo et al. (2008) to investigate a destination's area code as a variable in order to create a better understanding of customer retention. Empirical verification of $\mathrm{H}_{5}$ reveals a partial moderating effect of province on the relationship between Satisfaction and Retention (Table 5), but does not support a moderating effect in the relationship between the SQSC and Retention (Table 2). A possible reason for the results is that business tourists are more satisfied with their service experiences in Gauteng and KwaZulu-Natal than in the Western Cape (Table 6). Of particular note is the contribution made by the partial moderating effect of frequency of the province most visited on the relationship between Satisfaction and Retention. Another contribution to the literature is that business tourists visiting Gauteng and KwaZulu-Natal have a higher Retention score than those visiting the Western Cape (Table 6). It can be assumed that the business tourism products in Gauteng and KwaZulu-Natal satisfy the service quality needs of the business 
tourists more than the products in the Western Cape. Based on the discussions, it can be observed that hypotheses $\mathrm{H}_{1}, \mathrm{H}_{2}$ and $\mathrm{H}_{5.2}$ are supported, because these moderating relationships are significant.

By knowing the value of the moderated market segmentation variables (gender, age, and province visited), business tourist practitioners can focus solely on these variables in the planning, execution, and assessment of their business tourist-related activities. This means that the other non-moderating market segmentation variables (ethnic group and educational qualification) need not be addressed or catered for as service quality requirements for business tourists. By focusing on these findings, practitioners can develop and enhance satisfaction, and thereby establish and maintain the long-term retention and competitiveness of a business tourist destination, such as South Africa.

This study should help these practitioners to understand the inter-relationship between the SQSC and Satisfaction as the mechanism for enhancing Retention of business tourists. While the context of the study is limited to the business tourism industry, the results generally reinforce previous research on general customers and tourists, with reference to gender and age. The indicators that determine the different market segment needs of business tourists assist practitioners in understanding the service quality expectations of business tourists, which no other studies in a business tourist context have reported before. This study can be useful for business tourism managers wishing to produce demand focused theory relating to a specific country's demographics for a better competitive advantage in the business tourism market.

Although the study provides insights into the impact of using the SQSC, Satisfaction, and Retention to maximise business tourist behaviour in the business tourism industry, there are several possible limitations to the study. These include the use of cross-sectional data, and that the data were obtained from a single type of respondent, namely business tourists. Thus, any generalisations to other types of tourism sectors should be done with caution. Furthermore, $87 \%$ of the respondents who participated in this study were local business tourists, and only $13 \%$ were business tourists from abroad. The international business tourist portion was too small for a reliable interpretation of the information related to the number of times they had travelled to South Africa, the country they represented, as well as the number of days they spent in South Africa.

Five market segmentation variables were identified, of which gender was the only variable that fully moderated the relationship between the SQSC and Retention, and between Satisfaction and Retention. This finding may further encourage practitioners to focus on the specific needs of men and women at a business tourist destination. Future research may also explore the moderating effect of these market segmentation variables in a leisure setting or at an international event.

This study set out to determine whether market segmentation variables have a moderation effect on the prediction model in the prediction of tourist retention. A cross-sectional survey of South African business tourists yielded close to 500 usable data sets by respondents. Multi-variate statistical techniques confirmed that gender, 
age and province visited moderate the prediction model. The study objectives are hereby achieved.

Acknowledgement The University of Johannesburg for the financial support to conduct this study.

Open Access This article is distributed under the terms of the Creative Commons Attribution License which permits any use, distribution, and reproduction in any medium, provided the original author(s) and the source are credited.

\section{References}

Aguinis H (2004) Regression analysis for categorical moderators. The Guilford Press, London Alegre J, Garau J (2010) Tourist satisfaction and dissatisfaction. Ann Tour Res 37(1):52-73 Anon (2013) South Africa is Africa's top meeting host. Business Events Africa 33(8):24-25

Baron RM, Kenny DA (1986) The moderator-mediator variable distinction in social psychological research: conceptual, strategic and statistical considerations. J Pers Soc Psychol 51(6):1173-1182

Briggs S, Sutherland J, Drummond S (2007) Are hotels serving quality? An exploratory study of service quality in the Scottish hotel sector. Tour Manag 28:1006-1019

Brunner-Sperdin A, Peters M, Strobl A (2012) It is all about the emotional state: managing tourists' experiences. Int J Hosp Manag 31(1):23-30. doi:10.1016/j.ijhm.2011.03.004

Burnkrant RE, Thomas J, Page JR (1982) An examination of the convergent, discriminant, and predictive validity of Fishbein's behavioural intention model. J Mark Res 19(November):550-561

Chan YCL (2004) Performance measurement and adoption of balanced scorecards: a survey of municipal governments in the USA and Canada. Int J Public Sector Manag 17(3):204-211

Chang YW, Polonsky MJ (2012) The influence of multiple types of service convenience on behavioral intentions: the mediating role of consumer satisfaction in a Taiwanese leisure setting. Int $\mathbf{J}$ Hosp Manag 31(1):107-118

Chen NH, Huang SCT, Shu ST, Wang TS (2013) Market segmentation, service quality, and overall satisfaction: self-organising map and structural equation modelling methods. Qual Quant 47:969-987

Chi CGQ, Qu H (2008) Examining the structural relationships of destination image, tourist satisfaction and destination loyalty: an integrated approach. Tour Manag 29(4):624-636

Chou JS, Yeh CP (2013) Influential constructs, mediating effects, and moderating effects on operations performance of high speed rail from passenger perspective. Transp Policy 30:207-219

Cohen D, Gan C, Yong HHA, Chong E (2007) Customer retention by banks in New Zealand. Banks Bank Syst 2(1):40-55

Costa PT Jr, Terracciano A, McCrae RR (2001) Gender differences in personality traits across cultures: robust and surprising findings. J Pers Soc Psychol 81(2):322-331

Coussement K, Van den Poel D (2009) Improving customer attrition prediction by integrating emotions from client/company interaction emails and evaluating multiple classifiers. Expert Syst Appl 36:6127-6134

Crouch GI, Devinney TM, Louviere J, Islam T (2009) Modelling consumer choice behaviour in space tourism. Tour Manag 30:441-454

Dabholkar PA, Shepherd CD, Thorpe DL (2000) A comprehensive framework for service quality: an investigation of critical conceptual and management issues through a longitudinal study. J Retail 76(2):139-173

De Rojas C, Camarero C (2008) Visitor's experience, mood and satisfaction in a heritage context: evidence from an interpretation centre. Tour Manag 29:525-537

Ekiz EH, Bavik A, Arasli H (2009) RENTQUAL: a new measurement scale for car rental services. Tourism 57:135-153

Fishbein M, Ajzen I (1975) Belief, attitude, intention and behaviour: an introduction to theory and research. Addison-Wesley Publishing Company, Menlo Park 
Forgas-Coll S, Palau-Saumell R, Sánchez-García J, Fandos-Roig JC (2013) Airline website loyalty formation and the moderating effects of gender and education. Serv Busi 7:255-274

Frazier PA, Barron KE, Andrew PT (2004) Testing moderator and mediator effects in counselling psychology research. J Couns Psychol 51(1):115-134

George R (2011) Managing tourism in South Africa, 4th edn. Oxford University Press, Cape Town

Ha J, Jang S (2010) Perceived values, satisfaction, and behavioral intentions: the role of familiarity in Korean restaurants. Int J Hosp Manag 29(1):2-13

Han H, Ryu K (2006) Moderating role of personal characteristics in forming restaurant customers' behavioral intentions: an upscale restaurant setting. J Hosp Leis Mark 15(4):25-54

Homburg C, Giering A (2001) Personal characteristics as moderators of the relationship between customer satisfaction and loyalty: an empirical analysis. Psychol Mark 18(1):43-66

Hosany S, Witham M (2010) Dimensions of cruiser's experiences, satisfaction and intention to recommend. J Travel Res 49(3):351-364

Hsieh AT, Tsai CW (2009) Does national culture really matter? Hotel service perceptions by Taiwan and American tourists. Int J Cul Tour Hosp Res 3(1):54-69

Hudson S (1999) Consumer behavior related to tourism. In: Pizam A, Mansfeld Y (eds) Consumer behavior in travel and tourism. The Haworth Hospitality Press, New York, pp 7-23

Hutchinson J, Lai F, Wang Y (2009) Understanding the relationships of quality, value, equity, satisfaction and behavioural intentions amongst golf travellers. Tour Manag 30:298-308

Hye-Rin L, McKercher B, Kim SS (2009) The relationship between convention host and professional conference organisers. Int J Hosp Manag 28(4):556-562

Im S, Bayus BL, Mason CH (2003) An empirical study of innate consumer innovativeness, personal characteristics and new adoption behaviour. J Acad Mark Sci 31(1):61-73

Ishii K (2012) The impact of ethnic tourism on hill tribes in Thailand. Ann Tour Res 39(1):290-310

Ishikawa N, Fukushige M (2007) Who expects the municipalities to take the initiative in tourism development? Residents' attitudes of Amami Oshima Island in Japan. Tour Manag 28(2):461-475

Kaplan RS, Norton DP (1992) The balanced scorecard-measures that drive performance. Harv Bus Rev 70(7/8):71-75

Kaplan RS, Norton DP (2001) The strategy focused organisation: how balanced scorecard companies thrive in the new business environment. Harvard Business School Press, Boston

Kaplan RS, Norton DP (2008) The execution premium: linking strategy to operations for competitive advantage. Harvard Business Press, Boston

Kim BP, Murrmann SK, Lee G (2009a) Moderating effects of gender and organizational level between role stress and job satisfaction among hotel employees. Int J Hosp Manag 28(4):612-619

Kim WG, Yen NC, Kim YS (2009b) Influence of institutional DINESERV on customer satisfaction, return intention, and word-of-mouth. Int J Hosp Manag 28:10-17

Kim SS, Prideaux B, Chon K (2010) A comparison of results of three statistical methods to understand the determinants of festival participants' expenditures. Int J Hosp Manag 29:297-307

Kong M, Jogaratnam G (2007) The influence of culture on perceptions of service employee behaviour. Manag Serv Qual 17(3):275-297

Lee JH, Kim HD, Ko YJ, Sagas M (2011) The influence of service quality on satisfaction and intention: a gender segmentation strategy. Sport Manag Rev 14(1):54-63

Li X, Li X, Hudson S (2013) The application of generational theory to tourism consumer behavior: an American perspective. Tour Manag 37:147-164

Lin $\mathrm{H}-\mathrm{H}$ (2011) Gender differences in the linkage of online patronage behaviour with TV-and-online shopping values. Serv Bus 5:295-312

Liu Y, Jang S (2009) Perceptions of Chinese restaurants in the U.S.: what affects customer satisfaction and behavioural intentions? Int J Hosp Manag 28(3):338-348

Loureiro SMC, Kastenholz E (2010) Corporate reputation, satisfaction, delight, and loyalty towards rural lodging units in Portugal. Int J Hosp Manag 30:575-583

Mittal V, Kamakura WA (2001) Satisfaction, repurchase intent, and repurchase behaviour: investigating the moderating effect of customer characteristics. J Mark Res 38(1):131-142

Moore CW, Petty JW, Palich LE, Longenecker JG (2008) Managing small business: An entrepreneurial emphasis. South-Western CENGAGE Learning, West Yorkshire

National Department of Tourism (NDT) (ed) (2011) National Tourism Sector Strategy. NDT, Pretoria

Pakdil F, Aydin O (2007) Expectations and perceptions in airline service: an analysis using weighted SERVQUAL scores. J Air Trans Manag 13:229-237 
Palan KM (2001) Gender identity in consumer behaviour research: a literature review and research agenda. Acad Mark Sci Rev 20(10):1-26

Parasuraman A, Zeithaml VA, Berry LB (1988) SERVQUAL: a multiple-item scale for measuring consumer perceptions of service quality. J Retail 64(1):12-40

Pizam A (1999) Cross-cultural tourist behaviour. In: Pizam A, Mansfeld Y (eds) Consumer behaviour in travel and tourism. The Haworth Hospitality Press, New York, pp 393-411

Pyon CU, Lee MJ, Park SC (2009) Decision support system for service quality management using customer knowledge in public service organization. Expert Syst Appl 36(4):8227-8238

Rid W, Ezeuduji IO, Pröbstl-Haider U (2014) Segmentation by motivation for rural tourism activities in Gambia. Tour Manag 40:102-116

Ro H (2012) Moderator and mediator effects in hospitality research. Int J Hosp Manag 31(3):952-961

Ryan MJ, Bonfield EH (1975) The Fishbein extended model and consumer behaviour. J Consum Res 2(September): $118-136$

Sabiote CM, Frías DM, Castaneda JA (2013) The moderating effect of culture on overall perceived value in the online purchasing process. Serv Bus 7:83-102

Sanchez-Franco MJ, Ramos AFV, Velicia FAM (2009) The moderating effect of gender on relationship quality and loyalty toward Internet service providers. Inf Manag 46(3):196-202

Seo D, Ranganathan C, Babad Y (2008) Two-level model of customer retention in the US mobile telecommunications service market. Telecommun Policy 32:182-196

Severt D, Wang Y, Chen PJ, Breiter D (2007) Examining the motivation, perceived performance, and behavioural intentions of convention attendees: evidence from a regional conference. Tour Manag 28:399-408

Snipes RL, Thomson NF (2006) Gender bias in customer evaluations of service quality: an empirical investigation. J Serv Mark 20(4):274-284

Sullivan B, Estes C (2007) Measuring customer service quality in local government. Public Manag $36(1): 37$

Swart MP (2013) A business tourist service quality scorecard for predicting tourist retention. Thesis. University of Johannesburg. Johannesburg

Swart MP, Roodt G (2008) The development of a service quality scorecard for the business tourism industry. In: Proceedings of the 21st Southern African Institute for Management Scientists (SAIMS) Muldersdrift, South Africa

Swart MP, Roodt G (2009) A proposed model for predicting business tourist retention. In: Proceedings of the XXVI Pan Pacific conference. Shenzhen, China

Swart MP, Roodt G (2011a) The development and validation of a service quality scorecard in the business tourism industry. In: Proceedings of the XXVII Pan Pacific Conference. Daejeon, South Korea

Swart MP, Roodt G (2011b) Tourist satisfaction as a mediator between the service quality scorecard and tourist retention. In: Proceedings of the XXVII Pan Pacific Conference. Daejeon, South Korea

Taplin RH (2012) The value of self-stated attribute importance to overall satisfaction. Tour Manag 33(2):295-304

Tsoukatos E, Rand GK (2007) Cultural influences on service quality and customer satisfaction: evidence from Greek insurance. Manag Serv Qual 17(4):467-485

Udo GJ, Bagchi KK, Kirs PJ (2010) An assessment of customers' e-service quality perception, satisfaction and intention. Int J Inf Manag 30(6):481-492

Wakefield KL, Baker J (1998) Excitement at the mall: determinants and effects on shopping response. J Retail 74(4):515-539

Wiersma E (2009) For which purposes do managers use balanced scorecards? An empirical study. Manag Account Res 20(4):239-251 